\title{
La construcción de los "otros" en la cultura educativa: análisis de algunos discursos sociales y políticos sobre el docente
}

\author{
Juan Carlos González Faraco \\ Universidad de Huelva \\ faracoluhu.es
}

\section{Las reformas educativas como modelos culturales}

Las reformas son algo más que textos jurídicos o determinaciones gubernamentales. Tienen una fecha de referencia, pero en realidad se van gestando paulatinamente en un ambiente propicio, aunque también contribuyen, en buena medida, a crearlo o, al menos, a alentarlo. Coinciden con etapas social o políticamente críticas que, en parte, son reconstruidas, discursivamente hablando, por la propia reforma para enfatizar y reclamar su misma necesidad. A su sombra, y éste es un efecto muy apreciable, prosperan el debate y la circulación de ideas, acompañadas de una cierta hiperproducción de signos y símbolos. A veces, las reformas llegan a fabricar y alimentar historias globales de salvación, poderosas imágenes que convocan a la comunidad en pos de un futuro prometedor (Popkewitz, 1994 y 1999).

Como una ola, una reforma reordena las piezas del escenario educativo y resitúa a sus actores, pero no sólo espacialmente. Les otorga nuevos textos y nuevos papeles, discute su jerarquía, e intensifica el intercambio de representaciones mutuas entre unos protagonistas y otros. Estos movimientos, en parte erráticos, dan alas a la reidentificación de cada sujeto involucrado en el proceso educativo, de sí mismo y del otro. En el fondo, una reforma es, entre otras cosas, una competencia en torno a la reconfiguración de las identidades personales y grupales.

Sin duda, detrás de toda reforma educativa hay un proyecto político más o menos retóricamente descrito y, en consecuencia, un proyecto de ciudadano que suele ser sólo relativamente preciso (Marchesi, 2000). Y también un modelo, una imagen de la infancia y del alumno, y, desde luego, un modelo, una imagen del profesor. Estas imágenes modélicas son también relativamente precisas y se ven sometidas a un complejo e intenso proceso verbal que pone de manifiesto el contraste de pareceres entre los diversos actores educativos. Aunque las reformas pretenden esgrimir modelos sólidos y orientaciones diáfanas para la toma de decisiones, son tierra abonada para la división, a veces subterránea, la disputa y el desconcierto. Sus efectos son, por eso, contradictorios y paradójicos. Junto a la proyección optimista del futuro, crece la nostalgia de tiempos pasados aparentemente más seguros. Frente a la unidad argumental se proclama la fragmentación del discurso educativo.

Este trabajo no pretende desarrollar estas cuestiones tan sustantivas; tan sólo tenerlas en cuenta, como telón de fondo, en un análisis que se circunscribe al docente. Lo que pretendemos hacer no es más que descifrar, al menos en parte, cuáles son algunas de las imágenes que sobre el profesor podemos avistar y constatar en el clima educativo actual, que en nuestro país está marcado por la reforma de los noventa (González Faraco, 2000). Nos interesa saber cómo son relatadas estas imágenes, qué significado se les atribuye, qué grado de consenso concitan y cuál es su variabilidad. No podemos prescindir de la relevancia de los individuos en estos relatos, pero queremos insistir en que tratamos de 
dilucidar representaciones culturales, por tanto sociales, que se atienen a uno o varios modelos, en torno a los cuales se congregan los individuos aunque no de manera absolutamente uniforme.

Aunque sólo a título orientativo, nos inspiramos para este entendimiento de la cuestión en los debates que ha venido sosteniendo la antropología cognitiva en torno a la llamada "teoría del consenso" y el concepto de "modelo cultural". Si nos atenemos a las fuentes fundamentales (por ejemplo, Holland y Quinn, 1987; Shore, 1996; D'Andrade, 1995), un modelo cultural es un esquema, el "esqueleto" representativo de un determinado ámbito cultural, en el que se incluyen los sujetos, la estructura, las relaciones y los procesos que hay en ese ámbito. Lo primero y principal que conviene saber es que un modelo cultural tiene un sentido constructivo; es algo mediante lo cual se definen los elementos constitutivos (en nuestro caso, sólo los actores) de algún ámbito cultural (en nuestro caso, el educativo). En el modelo encontramos una representación de las asociaciones entre esos elementos y/o sujetos, cómo cada uno de ellos se relaciona con los demás y cómo un ámbito o dominio cultural funciona para expresarse y para expresarlos. Para decidir qué hacer o qué significan los otros y sus conductas en una situación dada, aplicamos nuestra comprensión del mundo tal como ha sido estructurada por nuestro modelo cultural. Sin duda, las reformas escolares pretenden representar, de cara a la comunidad educativa, y de cara al conjunto de la población, todo un modelo cultural reconocible, referencial y verosímil. Hasta qué punto ese modelo es compartido por cada uno de los miembros y subgrupos de esa comunidad es otra cuestión muy distinta, difícil de determinar.

Pero, aun teniendo en cuenta la elaboración y expresión individual de los modelos culturales (como puede verse en las entrevistas a los informantes), lo que hace que estos modelos sean verdaderamente culturales y no meramente individuales, es que los compartamos, en buena medida, con otras personas. Sin duda, los modelos culturales dependen en parte de atribuciones individuales de significado, pero su completa caracterización sólo es posible si tenemos en cuenta los significados compartidos. Cualquiera de las diversas teorías sobre estructuras mentales compartidas que recogen y organizan un contenido cultural, como el concepto de "habitus" de Boudieu (1984) o el concepto de "representación cognitiva compartida" de Romney y Moore (1998), podría ser útil en esta cuestión. Preferimos el concepto de "modelos culturales" porque está más elaborado como teoría de la cultura.

La utilidad de esta orientación teórica ha sido puesta de relieve en trabajos antropológicos sobre métodos de investigación, específicamente en el modelo del consenso cultural desarrollado por Romney, Weller y Batchelder (1986). Más que una técnica analítica, el modelo del consenso ha contribuido a la elaboración de una teoría de la cultura que enfatiza la importancia de lo que se comparte como elemento prominente de la definición del conocimiento cultural. El modelo del consenso capacita al investigador para determinar sin ambigüedades si hay suficiente acuerdo en las respuestas de un grupo de informantes a una serie de cuestiones estructuradas para que sea razonable inferir que todos ellos se integran en un modelo específico de ese dominio cultural. La teoría y los métodos de los modelos culturales y el análisis del consenso cultural podrían ser de gran provecho si se aplicaran al estudio de las culturas escolares o, más específicamente, al estudio del docente y a las imágenes que despierta en los diversos sectores de la comunidad educativa.

No vamos aquí a hacer una aplicación exhaustiva de ese método, pero sí aprovechar, como decíamos antes, algunas de sus premisas teóricas a modo de orientación o marco de referencia intelectual. No tenemos tampoco la pretensión (sería vana) de analizar una cuestión (los modelos culturales en torno al docente) tan vasta como ésta, ni de siquiera ofrecer una panorámica comprensiva del conjunto de un argumento tan intrincado. 
Nuestro objetivo es más modesto. Desde luego que no olvidamos que estamos tras la pista de un modelo cultural sobre la docencia para, primero, intentar acotarlo y, segundo, para vislumbrar hasta qué punto es compartido. Sin embargo, aquí sólo trataremos de registrar y analizar someramente las representaciones que sobre los profesores circulan por los discursos de los actores políticos y de algunos actores de la "sociedad civil". O, dicho de otra manera, establecer qué construcciones sobre el docente manejan o fomentan, y observar cuán diferentes o similares son.

Para ello prescindiremos de los textos legales y de la documentación en general, e iremos directamente al análisis de los discursos recogidos en un buen número de entrevistas obtenidas en el marco de un proyecto de investigación desarrollado entre 1998 y 2000, presto ya para producir informes con sus conclusiones finales. Nuestro trabajo aquí representa tan sólo un escarceo por uno de los subapartados de uno de los ámbitos de esta investigación, desarrollada en el último trienio por nueve equipos universitarios en otras tantas naciones y regiones europeas [1], distribuidas equilibradamente entre el norte y el sur.

\section{La construcción del docente según un proyecto europeo sobre política educativa}

Education Governance and Social Integration and Exclusion in Europe (EGSIE), que así se llama esta investigación, es un proyecto TSER (Targeted Socio-Economic Research) de la Dirección General XII de la Comisión Europea, coordinado desde el Departamento de Educación de la Universidad de Uppsala, Suecia, por el profesor Sverker Lindblad, con el concurso, como experto internacional, del profesor Thomas S. Popkewitz, de la Universidad de Wisconsin-Madison. Desde el primer momento, se sumó al proyecto un equipo australiano de la Universidad de Newcastle.

El proyecto se sitúa, temporalmente hablando, en el escenario postmoderno de la globalización, y más concretamente en la última década del siglo. Teóricamente se mueve en dos campos conceptuales extraordinariamente complejos y problemáticos: el de la equidad y el del conocimiento. En el primer caso se está aludiendo a "cuestiones de representación y acceso de los individuos y los grupos a las prácticas sociales y educativas" (Popkewitz y Lindblad, 1999, 2). El término "governance, dentro de esta perspectiva, -continúa la cita- es un concepto para reflexionar sobre y juzgar los significados a partir de los cuales las actividades (educativas) son controladas $\mathrm{u}$ orientadas para proporcionar un aceptable nivel de resultados en función de una serie de estándares sociales establecidos". La inclusión y la exclusión se definen en relación con el grado de participación que un determinado grupo logra en esos estándares.

En cuanto a la problemática del conocimiento, nos estamos refiriendo exactamente a "los sistemas de razón mediante los que se fabrican las identidades atribuidas a los diversos actores con el fin de ordenarlos y dividirlos" (Idem). Las consecuencias de estos sistemas de razón sobre la inclusión y la exclusión social son evidentes, en el sentido de que producen reglas y principios de distinción, división y diferenciación que regulan la acción y la participación de los sujetos en los diversos espacios en los que trazan su vida.

La hipótesis general del proyecto parte de la constatación de que, en marco de la reestructuración del capitalismo global y el replanteamiento de las relaciones entre la educación y la economía se ha producido recientemente una cascada de cambios en los sistemas educativos europeos. En muchos casos, como el español (Pereyra, Sevilla y Castillo, 1999), incluso se han acometido reformas escolares de mayor o menor alcance, auspiciadas por gobiernos "modernizadores de izquierdas" que han intentado explorar las posibilidades del modelo económico post-fordista retomando el debate sobre la educación en términos de equidad versus eficiencia. En otros, se han dejado notar los presupuestos 
de lo que comúnmente conocemos por "Nueva Derecha", en el sentido de "crear un cuasimercado dentro del cual las escuelas competirán" (Brown y Lauder, 1997, 176; Kenway, 1997). El proyecto EGSIE pretende analizar comparativamente estos cambios y reformas, como respuestas de las políticas educativas de las distintas naciones europeas, teniendo en cuenta, de un lado, que con el proceso de globalización están emergiendo similares y nuevas formas de gobierno de los sistemas educativos, con implicaciones problemáticas en todas la escalas de decisión; y de otro, que todo ello está teniendo un impacto directo en la capacidad de la educación para promover la integración y combatir la exclusión social, en Estados que se venían reclamando como "del Bienestar".

Los objetivos y, por ende, los contenidos, del proyecto se cifran en constatar y analizar los cambios recientes en las formas de gobierno (en el amplio sentido de "governance" que acabamos de relatar) de los sistemas educativos europeos, estableciendo las correspondencias y contradicciones entre estos nuevos patrones y las tradiciones y supuestos históricos de la escolaridad en Europa. Trata, a continuación, de dirimir las implicaciones de las nuevas formas de dirección política en la organización y diferenciación de los sistemas educativos europeos y, por fin, determinar los resultados de las diferentes estrategias político-educativas en la integración y exclusión social. Un botón de muestra de la extensa y minuciosa actividad investigadora realizada sobre estos tópicos queda reflejada en los informes previos ya elaborados y publicados (Lindblad y Popkewitz, 1999; Popkewitz, Lindblad y Strandberg, 1999; Lindblad y Popkewitz, 2000), sin citar la infinidad de borradores emitidos por cada equipo, amén del material "etnográfico" recogido (textos, colecciones estadísticas, entrevistas grabadas, etc.). No vamos aquí a listar esas actividades ya desarrolladas, a punto de emitirse, en estos momentos, los informes finales preceptivos. Pero sí vale la pena citar las grandes fases por las que ha discurrido la investigación:

- $1^{\mathrm{a}}$ Descripción en profundidad de los sistemas educativos involucrados, mediante el estudio de textos, estadísticas, investigaciones, etc. y elaboración de informes nacionales.

- $2^{a}$ Análisis del discurso de las instituciones y de los actores del sistema educativo: organismos internacionales, políticos y administradores, altos ejecutivos, directores de centros, profesores, miembros de la sociedad civil (directivos de asociaciones de padres, sindicatos, empresarios, etc.)

- $3^{\text {a }}$ Estudio de campo, mediante cuestionario, con escolares de enseñanza secundaria y preuniversitaria.

- $4^{a}$ Estudio final comparado: construcción de una tipología comparativa de países, formulación de hipótesis sobre la cuestión de los cambios en el gobierno de la educación y su impacto en la inclusión/exclusión social.

- $5^{\text {a }}$ Información y discusión de los resultados con agentes educativos en diferentes contextos.

Como puede fácilmente deducirse de este trayecto investigador, nosotros nos centraremos, exclusivamente, en la segunda fase. Y no en toda. Tan sólo en el análisis del discurso de los actores educativos, y particularmente, aunque haremos referencias a otras categorías analíticas, en el análisis de los contenidos que conciernen a la construcción del docente, con especial referencia al de secundaria, por haber sido esta etapa del sistema escolar la más aludida en las entrevistas realizadas.

\section{El discurso de los actores del sistema educativo: pautas metodológicas para su análisis}

El objetivo de los análisis que en su momento abordamos no era establecer "la verdad" de los discursos, su veracidad, su mayor o menor adecuación a la realidad (según se entiende este concepto en un marco epistemológicamente estructural) (Cherryholmes, 1999). 
Concebimos el discurso, siguiendo a Foucault $(1999,53)$, como "una violencia que se ejerce sobre las cosas, en todo caso como una práctica que les imponemos". Por eso, nuestro empeño era recoger, establecer e interpretar la gama de argumentos usados por los diversos actores educativos para hablar sobre los diversos tópicos de la investigación. Como dice Foucault $(1999,45-46)$, "¿qué es después de todo un sistema de enseñanza, sino una ritualización del habla; sino una cualificación y una fijación de funciones para los sujetos que hablan; sino la construcción de un grupo doctrinal cuando menos difuso; sino una distribución y una adecuación del discurso con sus poderes y saberes?". Eso era lo que nosotros pretendíamos identificar y, a ser posible, descifrar: los saberes, o las verdades (Simola, Heikkinen y Silvonen, 2000) que producen los sujetos implicados en la política educativa, a una u otra escala.

Las entrevistas, basadas en un cuestionario semiestructurado, sumamente abierto y muy flexible para facilitar la construcción del discurso con los menos condicionantes posibles y adaptarlo a las eventualidades de la entrevista, se realizaron siempre en los escenarios profesionales o laborales de los entrevistados. No teníamos interés por contemplar toda la variabilidad de discursos sobre la educación presentes en el conjunto de la nación. El proyecto EGSIE no trata de comparar, a la manera clásica, discursos nacionales, sino recopilar, analizar y, en todo caso, contrastar la diversidad de discursos presentes en la Unión Europea sobre las cuestiones del proyecto, sea en los organismos internacionales, sea en los altos estratos del sistema (System's Actors) a escala regional o nacional, sea en las escalas locales o propiamente escolares (School's Actors), sea, por fin, en algunos colectivos institucionales de la sociedad civil. Las entrevistas, en nuestro caso, se centraron, en dos espacios periféricos europeos del sur, uno peninsular, Andalucía, y otro extrapeninsular, Canarias.

Nuestra primera premisa, a la hora de analizar las entrevistas, fue rastrear cuidadosamente la construcción de las respuestas, desde la aparición inicial de argumentos del canon institucional-gremial de cada entrevistado, hasta la progresiva emergencia de sus interpretaciones personales. En general, conforme pasaban los minutos, el discurso "oficial" previsible se iba subjetivando y se enriquecía. Teníamos mucho interés en reconocer las diferencias interindividuales, relacionadas con el itinerario vital de cada sujeto. Para proceder al análisis del contenido de los discursos, se definieron tres categorías analíticas:

\section{a) Las historias proporcionadas por los sujetos}

Se estudian las respuestas en torno a los cambios habidos en la educación española en los últimos diez años. La reforma de 1990 es siempre el eje de los argumentos. Las respuestas revelan importantes diferencias de criterio entre los diversos sectores y también dentro de cada sector, entre distintos sujetos y también entre grupos de sujetos. Son frecuentes las alusiones a la problemática de la enseñanza secundaria y a las edades correspondientes. Las respuestas se bifurcan en dos direcciones: la primera, hacia un discurso optimista que resalta los cambios positivos; la segunda, hacia un discurso crítico que señala los problemas que han comportado estos cambios.

\section{b) El "gobierno" de la educación y su influencia en la inclusión y la exclusión social}

Aquí se recogen los argumentos sobre el tema central del Proyecto, la influencia de las nuevas prácticas de gobierno de la educación sobre los procesos de integración o exclusión social de los jóvenes. La investigación se ha centrado en las edades que coinciden con la enseñanza secundaria y en los procesos de transición entre esta etapa educativa y las siguientes, y entre la educación y el trabajo. Insistimos en que ha de entenderse el sustantivo "gobierno" (governance) referido a las prácticas políticas de gobierno o formas de acción a cualquier escala institucional o social, incluyendo la diaria 
toma de decisiones de los docentes en sus aulas.

\section{c) La construcción de los sujetos}

En este subapartado nos queremos situar para abordar el objeto de nuestra comunicación. En él se integran los contenidos relacionados con el modo en que los diversos actores se construyen entre sí, es decir, cómo hablan de los demás. Es el momento de adelantar que las respuestas revelan, por regla general, una escasa autocrítica, de manera que las culpas de los problemas señalados van habitualmente a parar a los "otros", en un cruce de "acusaciones" de mayor o menor intensidad. Las "construcciones" producidas por los entrevistados aluden a los estudiantes, a las familias, a los políticos, a los sindicalistas, a todos los actores en general, pero tienen un destinatario común que, en ningún caso, cae en el olvido, el profesor, con reiteradas referencias al profesorado de secundaria, etapa educativa sobre la que, como ya adelantamos, giran prioritariamente los discursos recogidos. Cosa lógica, por otro lado, puesto que esta etapa, y sobre todo, su tramo obligatorio, constituye la novedad más llamativa de la reestructuración del sistema escolar español a raíz de la LOGSE Es, por tanto, en la imagen de la mayoría, la etapa más crítica, menos acabada, y más problemática (Esteve, 2000).

\section{El profesor en el discurso de los otros actores del sistema educativo.}

Es menester empezar diciendo, a manera de aviso o cautela, que las dimensiones de un trabajo como éste obligan a una cierta simplificación de lo que es extenso y complejo. Así que las referencias que siguen, como las ya desgranadas con anterioridad, no pueden abarcar en toda su riqueza los discursos analizados, que quedan, por eso, algo esquematizados. Nuestras afirmaciones son sólo impresiones de conjunto, nunca como descripciones inapelables, y menos aún conclusiones definitivas.

Antes de esbozar las imágenes que el docente suscita en los distintos actores entrevistados, establezcamos algunas consideraciones básicas que, si bien no resumen la generalidad de los discursos, dan algunas pistas sobre lo que, a nuestro juicio, son algunos de sus argumentos más sugerentes y acaso más comprensivos. Estas consideraciones conciernen a una fractura, a un proceso de cambio, a una paradoja y a una aparente contradicción. En todos estos goznes críticos se ve afectado, de una u otra manera, el docente, como persona o como profesional, o como ambas cosas al mismo tiempo.

Partamos de la constatación de una fractura discursiva crucial, la que divide en dos bandos, no vamos a decir irreconciliables pero sí encontrados, a los actores del sistema (políticos, altos administradores) y a los actores de la escuela, profesores y directivos de los centros principalmente. Para los primeros, la reforma educativa española encarna un modelo indiscutible, aunque no exento de problemas, y un punto histórico, e irreversible, de inflexión en el desarrollo del sistema escolar. Para los actores de la escuela, para los profesores sobre todo, la reforma es retórica y ajena a la realidad ("hecha en los despachos", como afirma algún entrevistado).

El proceso de cambio, al que nos referíamos antes, conduce a una paradoja que se observa nítidamente en las entrevistas a los actores políticos. El espíritu igualitarista de la reforma se mantiene en los textos y en los discursos públicos, pero subrepticiamente (y, a veces, abiertamente) despuntan síntomas de ambivalencia y hasta de escepticismo ante su viabilidad práctica. En efecto, va ganando terreno el discurso de la eficiencia, mientras se va poniendo en duda por un buen número de los entrevistados (incluyendo actores políticos en activo en gobiernos regionales) la capacidad real de inclusión del sistema escolar. La paradoja cae de su peso: al mismo tiempo que se proclama, como valor positivo esencial de la nueva escuela, su sentido integrador, diversificado e inclusivo, se 
añora una escuela eficiente que produzca sujetos adaptados, emprendedores, encarnación de lo que T. Popkewitz ha llamado con mucho tino el "cosmopolitan self". Una escuela, en fin, en la que, cabe temerse, germinarían nuevas formas de normalización productoras de nuevos excluidos. Como es notorio, en un sector nada desdeñable del profesorado de secundaria se ha instalado parasitariamente esta añoranza de la "calidad" perdida, como un modo de resistencia ante los cambios en esa etapa escolar (Esteve, 2000).

Y, por fin, una aparente contradicción, la que nace de mantener simultáneamente como igualmente necesarias la democratización del sistema, la participación comunitaria en su gestión, la autonomía de gobierno y gestión de los centros escolares y, del otro lado, la profesionalización de las funciones directivas. Desde luego, ésta no es la única situación contradictoria observable, pero es un buen botón de muestra. Lo que nos hace pensar que es ahora, en estos precisos momentos, cuando verdaderamente se está produciendo la inflexión en el desarrollo de la reforma educativa, su decantación hacia una dirección aún indecisa pero en parte previsible.

En este marco de transición y discursos ambivalentes, la figura del profesor, en las narraciones de los diversos actores, concita, como dijimos, un extraordinario interés. Sólo haremos mención a los juicios que los docentes merecen a los actores políticos del sistema y a los actores sociales (asociaciones de padres, organizaciones empresariales y sindicatos). Una vez más hay que insistir en la heterogeneidad de las respuestas dentro de cada sector y las limitaciones de la muestra entrevistada [2].

La fractura antes aludida en torno a la reforma educativa deja su huella en las opiniones que los actores políticos vierten sobre el profesor. Consideran que el profesor encarna el pilar básico para el correcto desarrollo de la reforma educativa, pero, desgraciadamente, se muestran renuentes (sobre todo en secundaria) ante las exigencias que su nuevo rol de "educador" conlleva. Los textos que siguen, extraídos de las extrevistas, pueden ilustrar estas ideas:

\footnotetext{
"El modelo actual es un modelo que exige cada vez más al profesor, en estas edades de adolescente $y$, por tanto, de secundaria obligatoria y bachillerato, no sólo conocimientos de su materia, que eso en su inmensa mayoría los tienen, sino también de educador, por tanto, un conocedor de la pedagogía, una persona que pueda convertirse en un referente a la hora de llevar adelante el traslado de actitudes, de comportamientos de valores...".

"...el profesorado quiere convertirse en mero trabajador que va al centro y echa unas horas igual que el que va a una fábrica y eso hace que la educación pierda... Yo creo que el profesorado tiene una responsabilidad y tiene que asumirla, lo que no puede es considerar que la responsabilidad es siempre de los demás y que su trabajo es meramente instrumental...".
}

Las respuestas destacan la urgencia de la adaptación del profesor a este nuevo rol, aunque reconocen que no es una tarea fácil, por razones diversas. Entre ellas, la caída de su prestigio social, unida a la recurrente culpabilización de que es objeto por parte de las familias. Pero sobre todo, por su condición funcionarial y su pérdida de ideales, de compromiso vocacional.

\footnotetext{
"Hay una cierta disfunción entre el esquema funcionarial y la autorresponsabilidad en el trabajo, tal como ahora mismo está diseñado y organizado. La figura del funcionario choca muchas veces con esta necesidad de responsabilidad o con la posibilidad de ejercer un liderazgo, que se ve dificultada por la oposición de los compañeros."
}

Los entrevistados se decantan por la profesionalización del ejercicio docente acompañada por un cambio de raíz en su formación (principalmente para el profesorado de secundaria), y, unánimemente, por la profesionalización de la función directiva y la revisión de las prerrogativas que, como funcionario, tiene el docente, al que acusan de obstaculizar las decisiones o, al menos, limitar los efectos de la política educativa diseñada por la administración correspondiente. Los entrevistados extienden algunos de estos juicios a los sindicatos de profesores, en los que ven un creciente estilo 
"...tenemos que ir a una profesión de profesor, $y$, por tanto, un profesor no puede ser una persona que ha estudiado una carrera de carácter técnico, la que sea, y que le da bagaje para ser historiador del arte, un geógrafo, un físico, un químico... yo creo que el modelo exige una titulación de profesor de secundaria con todos los elementos que acompañan a un nuevo profesor...".

"...los directores deben sentirse parte de la cadena de la organización, para que esto funcionara, y ellos son la pieza clave. Aquí nosotros planificamos, decidimos y puede que nos equivoquemos, pero los que de verdad tienen que llevar esto hasta sus últimas consecuencias son los directores. Es la profesionalización de la función directiva, desde todos los puntos de vista, gestión económica, toma de decisiones directivas, no sólo académicas, creo que el sistema de selección que hay para los directores no es el idóneo...".

Como era de esperar, las entrevistas de los actores de los distintos estamentos de la "sociedad civil" (APAs de centros públicos, Sindicatos de profesores y Organizaciones Empresariales) arrojan notables diferencias entre unos y otros en todos los contenidos abordados y también en lo que concierne al profesorado. Coinciden, no obstante, en señalar, como los demás actores entrevistados, la Educación Secundaria Obligatoria como el mayor foco de conflictos. Coinciden igualmente en enfatizar la importancia capital del profesor en la educación, particularmente en una época de cambios educativos que son, a su vez, el reflejo de grandes cambios políticos y sociales. Sin duda, poco tiene que ver el profesor actual con su imagen añeja de hombre autoritario y distante de las familias y con su irónico estatus de notable local y, al mismo tiempo, de menesteroso.

Los directivos de asociaciones de padres de centros públicos apuntan las nuevas condiciones a las que se ve impelido el ejercicio docente tras la reforma y atisban un cierto desencanto entre el profesorado. En su favor, también reconocen que se han multiplicado las tareas que ahora debe acometer el profesor, por lo que se ve seriamente sobrecargado.

\footnotetext{
"La sociedad en general plantea objetivos imposibles de conseguir por parte del profesor, cual es que sea un padre, que supla en su totalidad a los padres o a la sociedad ante el hecho educativo... En primaria se plantea más un profesor que sea un cuidador, más guardería, en general, y del profesor de secundaria se demanda que tutele, que sea más tutor, que se preocupe más de la educación de sus hijos que la sociedad, en general, ha aparcado en la institución escolar".

"...No se le pide ni legalmente, ni está escrito en ningún lugar que el profesor sea un psicólogo, un cura, un padre, un profesor y a la vez un psiquiatra, para nada".
}

El profesorado, en esta situación de agudos cambios, se encuentra en un momento crítico, dividido entre quienes rechazan esos cambios (en la secundaria abundan) y quienes alientan esperanzas de que esta reforma traerá beneficios, en términos de mayor inclusión social. Al hablar de la indisciplina como uno de los problemas más graves de la escuela actual, los padres vuelven a reiterar la idea de "una doble cultura" docente que identifican con el profesorado de primaria y el de secundaria.

\footnotetext{
"..los hay que, con mentalidades antiguas, tienen problemas por su poca flexibilidad, por no adaptarse a los nuevos tiempos... Otro sector de profesores, que están más comprometidos con la reforma, están preparados para trabajar con todo tipo de alumnado y consideran que son una ayuda al alumno y se cargan más de paciencia y pueden llevarlo mucho mejor".

"... en la cultura primaria sí que están habituados a un tipo de trabajo (...), mientras tanto en secundaria, pues es una cultura nueva, todavía no está asumida por el profesorado. Ahora, creerse, creerse la Logse, creerse el nuevo sistema pues hay un 60,50\% de profesores que no se lo creen".
}

Padres y madres esperan que sus hijos sean educados por profesores motivados, vocacionales, ilusionados y bien formados y, sin embargo, ven a su alrededor demasiados síntomas de lo contrario: desilusión, escasa preparación, poca especialización, interinidad en el puesto de trabajo... Los sindicalistas, por su parte, se duelen de la caída de valor social de la docencia como profesión y reclaman una redemocratización de la gestión 
escolar.

\begin{abstract}
"Habrá que procurar que la figura del profesor, que no es una figura incombustible, es decir, que tiene que tener prestigio y ese prestigio no solamente va porque se esté más formado, sino porque hemos visto que hay que darle más apoyo de la administración, más formación, retribuciones, horarios, aulas, ratios, etc. y una serie de instrumentos que son fundamentales".

"En los tiempos de hoy veo yo que el profesorado está totalmente, muchas veces, muy aislado y desprotegido".

"Un director jerarquizado, como señala la Lopegce, una ley que habría que derogar inmediatamente porque se contradice con la autonomía de los centros, con una enseñanza participativa y participada".
\end{abstract}

Por su lado, los empresarios, encendidos defensores de una educación eficaz y capacitadora, estrechamente conectada con el mercado, recelan del profesorado público y su estatuto laboral de funcionario, en el marco de una crítica global de la reforma escolar a la que acusan de retórica e "ideológica".

"Unos en una mesa diseñan un sistema que otros, en la realidad social, no demandan".

Sin la menor reserva, demandan una reducción de los sistemas de elección democrática de los directivos escolares, a favor de una estricta profesionalización siguiendo el modelo de una empresa.

".. es un grave error la excesiva participación en la dirección efectiva de las instituciones...".

Digamos, para concluir, que estamos, y en esta afirmación hay consenso entre todos los sectores entrevistados, ante un nuevo rol docente, por ahora impreciso, fruto de una conjunción de cambios intra y extraeducativos, que sin embargo no logra, por ahora, perfilarse ni menos aún generalizarse. Ésa es la cara y la cruz, la imagen dilemática de unos profesionales que, en la percepción de otros actores de la educación, son, por una parte, sustanciales para el desarrollo de las reformas escolares y, por otra, uno de sus mayores lastres. Para las asociaciones de padres de centros públicos, "desarrollo" quiere decir adecuación a los tiempos, ilusión y renovación, mientras que para el empresariado "desarrollo" quiere decir eficacia y aprendizaje de las pautas de la empresa y el mercado. Estamos, una vez más, ante otro disenso discursivo sobre la figura docente, que se suma a los anteriormente enunciados, y a los que crónicamente viene padeciendo el profesor, como explicaba J. Vera hace ya una década (1992).

En medio de este cruce de imágenes encontradas, el profesor, en boca de todos, anda a la búsqueda, como los personajes de Pirandello, de su nuevo papel en un teatro escolar todavía en construcción. De cuál será ese papel sólo cabe hacer conjeturas. Por ahora, todo lo que tenemos es un conjunto fragmentario de imágenes que aún están lejos de constituir un modelo suficientemente compartido por los actores de la cultura educativa, incluyendo los propios docentes. Simola y otros (2000, 88-95) han analizado el nacimiento y configuración del profesor moderno a partir del triángulo interpretativo que reúne, como factores capitales, al sujeto, al conocimiento y al poder. En el cruce de estos tres factores se han ido construyendo "las verdades" del profesor moderno, se ha ido gestando, y variando, su imagen social basada en la ejemplaridad moral y se ha definido su identidad profesional. Si aplicamos un análisis parecido, tomando en cuenta además las prospecciones "empíricas" más fiables, lo único que podemos afirmar es que todavía está por ver cuáles van a la ser "las verdades" del profesor postmoderno. Del mismo modo que está todavía por ver cuál será el destino definitivo de la cultura escolar en el tiempo que nos aguarda.

\title{
Bibliografía
}

BROWN, Ph. y LAUDER, H. (1997) Education, Globalization and Economic 
Development, en HALSEY, A. H; LAUDER, H.; BROWN, Ph. y WELLS A. S. Education. Culture, Economy and Society. New York, University Press, Oxford, 72-192.

CHERRYHOLMES, C. (1999) Poder y crítica. Estudios postestructurales en educación. Barcelona, Pomares-Corredor

D'ANDRADE, R. G. (1995) The Development of Cognitive Anthropology. Cambridge, Cambridge University Press.

ESTEVE, J. M. (2000) La formación del profesorado en clave de futuro, en RODRÍGUEZ NEIRA, T.; PEÑA, J. V. y HERNÁNDEZ, J. Cambio educativo: presente y futuro. Oviedo, Servicio de Publicaciones de la Universidad, 33-66.

FOUCAULT, M. (1999) El orden del discurso. Barcelona, Tusquets.

HOLLAND, D. y QUINN, N. (eds.) (1987) Cultural Models in Language and Thought. Cambridge, Cambridge University Press.

KENWAY, J. (1997) La educación y el discurso político de la nueva derecha, en BALL, S. J. (Comp.) Foucault y la educación. Disciplinas y saber. Madrid, Morata,169-207.

LINDBLAD, S. y POPKEWITZ, T. S. (eds.) (1999) Education Governance and Social Integration and Exclusion: National Cases of Educational Systems and Recent Reforms. Uppsala University, Department of Education (Uppsala Reports on Education 34).

LINDBLAD, S. y POPKEWITZ, T. S. (eds.) (2000) Public discourses on education governance and social integration and exclusion: Analyses of policy texts in European contexts. Uppsala University, Department of Education (Uppsala Reports on Education 36).

MARCHESI, A. (2000) Controversias en la educación española. Madrid, Alianza.

PEREYRA, M.; SEVILLA, D. y CASTILLO, P. J. (1999) The Spanish Educational System: A Report, en LINDBLAD, S. y POPKEWITZ, T. S. (eds.) Education Governance and Social Integration and Exclusion: National Cases of Educational Systems and Recent Reforms. Uppsala University, Department of Education, 171-203.

POPKEWITZ, T. S. (1994) Sociología política de las reformas escolares. El poder-saber en la enseñanza, la formación del profesorado y la investigación. Madrid, Morata.

POPKEWITZ, T. S. (1999) Reforma, conocimiento pedagógico y administración social de la individualidad: la educación escolar como efecto de poder, en IMBERNÓN, F. (coord.) La educación en el siglo XXI. Los retos del futuro inmediato. Barcelona, Grao, 121-146.

POPKEWITZ, T. S.; LINDBLAD, S. y STRANDBERG, J. (1999) Review of Research on Education Governance and Social Integration and Exclusion. Uppsala University, Department of Education (Uppsala Reports on Education 35).

ROMNEY, A. K. y MOORE, C. C. (1998) Toward a theory of culture as shared cognitive structures, Ethos, 26, 314-337.

ROMNEY, A. K.; WELlER, S. C. y BATCHELDER, W. H. (1986) Culture as consensus: A theory of culture and informant accuracy, American Anthropologist, 88, 313-338.

SIMOLA, H.; HEIKKINEN, S. y SILVONEN, J. (2000) Un catálogo de posibilidades: historia foucaultiana de investigación de la verdad y la educación, en POPKEWITZ, T. S. y BRENNAN, M. (comp.) El desafío de Foucault. Discurso, conocimiento y poder en la educación. Barcelona, Pomares-Corredor, 81-106.

VERA VILA, J. (1992) Elementos para el análisis de la imagen social de los profesores, Teoría de la Educación. Revista Interuniversitaria, IV, 139-149.

WHITTY, G. E. (2000) New School for New Times? Education Reform in a Global Context, en POPKEWITZ, T. S. (ed.) Educational Knowledge: Changing Relationships between the State, Civil Society and the Educational Community. Nueva York, Suny Press. 


\section{Notas}

[1].- Universidad de Helsinki, Finlandia; Universidad de Islandia; Universidad de Uppsala, Suecia; Universidad de Keele, Escocia; Universidad J. W. Goethe, Franfurkt del Meno, Alemania; Colegio Universitario de Westhill, Birmingham, Gran Bretaña; Universidad de Lisboa, Portugal; Universidad de Atenas, Grecia; Universidad de Granada, España.

[2].- Como se apuntó con anterioridad, la mayor parte de la muestra procede de las comunidades andaluza y canaria. En ambos casos, fueron entrevistados los altos cargos de las respectivas administraciones educativas (consejeros, directores generales) y de los consejos escolares regionales, jefes de servicios de inspección, altos cargos (por ejemplo, parlamentarios) relacionados con la política sobre el menor directivos de las asociaciones de padres de centros públicos, miembros de las direcciones de los sindicatos de la enseñanza, dirigentes de las organizaciones empresariales. En total, varias decenas de largas entrevistas, grabadas, transcritas y rigurosamente analizadas. Los textos entrecomillados que ilustran nuestros comentarios están extraídos de esas transcripciones. Por razones obvias, no se dan datos del entrevistado.

(C) Ediciones Universidad de Salamanca 